\title{
Median cleft of the upper lip and maxilla
}

INSERM

\section{Source}

INSERM. (1999). Orphanet: an online rare disease and orphan drug data base. Median cleft of the upper lip and maxilla. ORPHA:141239

Median cleft of the upper lip and maxilla is a rare, congenital, developmental defect during embryogenesis characterized by a midline vertical cleft through the upper lip and premaxillary bone (can also involve the nasal septum and central nervous system). The phenotypic spectrum is highly variable (ranging from a simple vermillion notch to a wide complete cleft) and hypo/hypertelorism, telecanthus, monophthalmia, flat or cleft nose, wide columella, median alveolar cleft and cranial malformations may be associated. 